paralysed and then develop a septicæmia as the bacteria penetrate into the body cavity. If the same culture is injected into the body cavity, the organisms multiply and produce a septicæmia but no paralysis occurs. The spores themselves are harmless if fed without the protein crystals, although they cause a septicæmia without paralysis if injected into the body cavity. The protein crystals can be extracted from the bacteria and cause paralysis and death if fed to the larvæ, but not if injected into the body cavity.

It seems, therefore, that the protein crystals are necessary for the penetration of the bacteria through the gut wall, and that the protein itself requires to be activated by the gut contents before it becomes toxic.

Dr. Norris also discussed the possible relationships between $B$. cereus, $B$. thuringiensis, $B$. sotto and $B$. anthracis. It is quite clear that there are a number of interesting problems to be solved in connexion with the pathogenicity of this group of organisms.

Dr. W. Mulligan (University of Glasgow) described the results of recent work on parasitic bronchitis of cattle which has been done at the University Veterinary School. This disease, caused by the lung worm Dictyocaulus viviparus, is responsible for serious debility among calves both in Britain and abroad. Severe attacks can be fatal. The disease may sometimes be cured by drugs which destroy the worm in the bronchi, but the treatment is usually too late to prevent severe damage to the lungs. Nevertheless, cattle gradually develop a satisfactory immunity after repeated exposure to natural infections. Dr. Mulligan and his colleagues have shown that calves can be protected against experimental infections of lung worms by injections of immune sera from animals which have recovered from the disease. This demonstration of the passive transfer of immunity has shown beyond all reasonable doubt that calves can produce protective antibodies against Dictyocaulus viviparus. The knowledge that circulating antibody can protect calves is of great value and a step forward in our understanding of the disease. Unfortunately, for practical reasons, this method of immunization cannot be used on the average farm. There is little doubt that the best method of prevention would be to find some means of artificially inducing an active immunity in otherwise susceptible animals. Attempts to immunize calves with various preparations of dead lung worms were apparently not very successful.

As natural infections gradually produce an active immunity, a trial was made with living vaccines consisting of larvæ which had been exposed to X-rays . It was hoped that larvæ treated in this way would survive for long enough in the calf to stimulate an active immunity and yet be incapable of causing progressive disease. Living vaccines of this type show great promise. It is thought that two doses of vaccine may give the best results, and an intensive trial is being made of this method. If these trials are successful, this vaccine should be of the greatest value to cattle owners in all parts of the world.

Dr. J. J. Bullen (Rowett Research Institute) discussed some of the factors which can influence the multiplication of pathogenic bacteria within a host. Examples were chosen from two experimental infections, enterotoxæmia of sheep and Clostridium welchii type $A$ infections in embryonated hen's eggs.

The organism responsible for enterotoxæmia of sheep, $C l$. welchii type $D$, is a normal inhabitant of the intestine. In certain circumstances, these bacteria multiply extremely rapidly and produce large quantities of toxin which is absorbed and kills the sheep. The disease cannot be reproduced in normal sheep fed on ordinary diets such as hay even if large numbers of $C l$. welchii type $D$ are introduced directly into the intestine. Viable counts of the bacteria in the living animal show that the bacteria cannot multiply fast enough to maintain their numbers and are soon removed by the normal flow of the intestinal contents. If the diet is suddenly changed, to wheat, for example, and the sheep overeats, the rumen becomes filled with undigested food. In the intestine this provides an ideal substrate for $C l$. welchii type $D$. Very large numbers of the bacteria accumulate in the intestine. Large quantities of toxin are produced and the animal dies from acute enterotoxæmia. Thus, the diet of the sheep appears to play an important part in the development of this disease.

The experiments with eggs show that suitable antisera and, in certain circumstances, normal sera, can protect embryonated hen's eggs against normally fatal infections with $C l$. welchii type $A$. The sera and bacteria are injected into the allantoic cavity. In unprotected eggs the organisms grow in the allantoic fluid and then invade the tissues of the embryo. In protected eggs the growth of the bacteria stops after an hour or two. There is no cellular response on the part of the host and no phagocytosis. Experiments of this kind appear to be useful for investigating the effect of sera on the growth of pathogenic organisms in the living host.

J. J. BULlen

\title{
CHARGE-TRANSFER PROCESSES
}

\begin{abstract}
A SYMPOSIUM on "Charge Transfer Processes", sponsored by the division of the Chemical Institute of Canada devoted to physical chemistry, was held during September 4-5 at the University of Toronto. The meeting, which had been organized under the chairmanship of Dr. B. E. Conway (University of Ottawa), was concerned with various aspects of the physical chemistry of reactions in which transfer of a formal charge occurs. Both homogeneous redox reactions and heterogeneous electrochemical reduction and oxidation processes were considered. About seventy-five physical chemists from the United States, Great Britain and Canada attended the academic sessions. Twenty-
\end{abstract}

seven papers were presented, and each author was allowed ten minutes to describe the essential results of his work, all papers having been preprinted and circulated to participants several weeks before the meeting. About half the total time of the meeting was devoted to erudite and lively discussion of the papers presented. The meeting was honoured by the presence of a number of invited speakers from overseas, including Dr. D. J. G. Ives (Birkbeck College, London), Dr. J. E. B. Randles (University of Birmingham) and Dr. R. Parsons (University of Bristol). Prof. A. Frumkin (Academy of Sciences, Moscow), who had been invited, sent a paper for presentation but was regrettably unable to be present. On the 
evening of September 4, participants at the symposium repaired to St. Michael's College for a reception and later took dinner at the Howard Ferguson Hall.

Prof. F. E. W. Wetmore (University of Toronto) opened the meeting by welcoming the participants. The first session, on "Homogeneous Processes", with Dr. B. E. Conway in the chair, was opened with a paper by Dr. H. Taube (University of Chicago) on bridging and simple ligand effects in electron transfer reactions ; Dr. Taube discussed changes which took place in the inner and outer co-ordination spheres of ions when these ions underwent oxidation or reduction. This was followed by theoretical contributions by Dr. K. J. Laidler (University of Ottawa) on electron-transfer reactions in aqueous solutions, and by Dr. R. A. Marcus on electrochemical and chemical. electron transfers. In these papers the factors involved in the electron transfer process and the solvent redistribution which occurs upon the transfer of a charge were examined. In the paper by Dr. K. J. Laidler, repulsion effects which arise upon the approach of ferrous and ferric ions in aqueous solution were calculated quantitatively, allowing for dielectric saturation. Electron transfer occurs by tunnelling. An optimum free-energy barrier exists for which the rate constant has a maximum value. A free energy of activation in good agreement with that determined by experiment was deduced. The applicability of the Franck-Condon principle to these processes was discussed at length. Dr. J. Halpern (University of British Columbia) examined the applicability of the principle of equi-valence change to inorganic oxidation-reduction reactions in terms of the kinetic parameters of a number of selected redox reactions. Drs. I. H. Henderson, R. L. Haines, E. G. Lovering and E. J. Casey (Defence Research Board, Canada) presented data on the equivalent redox potential of aqueous solutions under $\gamma$-irradiation. The session on homogeneous processes was concluded with two papers on the mechanism of anomalous proton mobility in hydrogen-bonded systems. Dr. M. Kilpatrick (Illinois Institute of Technology) discussed the limiting conductance of lyonium and lyate ions with particular reference to some anomalous non-aqueous systems, and Dr. B. E. Conway, speaking on the role of proton tunnelling in certain charge transfer processes, described measurements on the conductance of heavy-ice and discussed the theoretical significance of the ratio of mobilities of hydrogen ions and deuterium ions in water, heavywater and the corresponding ices, in terms of a proton-tunnelling mechanism. A theoretical examination of the possibility that proton tunnelling also occurred in certain electrode processes involving hydrogen was given and criteria for recognition of such an effect were presented.

The second session, with Dr. J. E. B. Randles in the chair, was devoted to the mechanism of cathodic electrochemical reactions. The mechanism of electrolytic silver deposition was discussed in a paper by Drs. W. Mehl and J. O'M. Bockris, who had used a galvanostatic technique. The results, together with certain theoretical considerations, led to the conclusion that surface migration of adsorbed silver atoms or 'partial ions' was the rate-determining process at low cathodic potentials, while ionic transfer from the double-layer to the surface was the slow step at higher potentials. Dr. C. V. King (New York University) discussed the kind of information that can be obtained from studies of exchange between metals and their ions in solution, and emphasized that care must be taken in the interpretation of exchange data owing to complications arising from bulk diffusion and other factors. The mechanism of growth of electrolytic metal whiskers was discussed in a paper by Dr. D. A. Vermilyea (General Electric Co.) in terms of the theory of crystal growth and the role of adsorbed inhibitors. Some abnormal hydrogen electrode reactions at gold were described by Dr. D. J. G. Ives (University of London) and a desorption reaction involving $\mathrm{H}_{2}+$ molecule-ions was discussed in an attempt to rationalize observations concerning reduction of tungstic oxide 'at a distance' from the electrode. Mr. A. Antoniu and Dr. F. E. W. Wetmore (University of Toronto) gave some further data on the hydrogen evolution reaction at silver. Inflected Tafel lines exhibiting slopes of 0.059 and 0.112 were observed as found in previous work, and the heats of activation $(\Delta H \neq)$ were determined for the two parts of the lines. A difference of about five kilocalories in $\Delta H \neq$ for the two processes involved was deduced; a change of mechanism of the reaction with increasing cathodic potential was indicated. Experiments on transport of hydrogen through palladium-clad electrodes were described in a paper by Drs. S. Schuldiner and J. P. Hoare (U.S. Naval Research Laboratory). Diffusion was detected by measurement of the polarization built up on the non-polarized side of a diaphragm electrode. The effect of cladding other metals (iron, nickel, gold) with palladium was examined.

The third session, on September 5, with Dr. B. E. Conway in the chair, was concerned with electrochemical reductions other than those involving hydrogen or metal deposition. Dr. J. E. B. Randles discussed the determination of kinetic parameters of redox reactions from current-potential curves and by a.c. impedance methods and referred to experimental results on the $\mathrm{V}^{\mathbf{3}+/} / \mathrm{V}^{\mathbf{2}}+$ reaction at mercury electrodes. The two methods give similar results if appropriate calculation of concentration polarization effects is made. The mechanism of reduction of chloraquochromium-III ions in acid media, studied at the dropping mercury electrode, was discussed in a paper by Drs. H. Elving and B. Zemel (University of Michigan). At low acid concentrations a dual electron-transfer mechanism involving the electrode and chromium-II ions is suggested, while for $\left[\mathrm{CrCl}_{2} .4 \mathrm{H}_{2} \mathrm{O}\right]+$ in $12 \mathrm{M}$ hydrochloric acid a simple direct electron-transfer process is indicated. Dr. M. J. Allen (Ciba) described some problems in the study of organic electrochemical reductions.

A group of papers then followed on anodic processes. Dr. E. S. Snavely and N. Hackerman (University of Texas) described some analytical and coulombic studies on the anodic passivation of iron, and Dr. M. Cohen (National Research Council of Canada) discussed the formation and properties of passive films formed on iron under various conditions, for example, the presence or absence of oxygen or the presence of inhibiting ions. Some theoretical considerations on the mechanism of growth of anodic oxide films were presented by Dr. L. Young (British Columbia Research Council). Dr. B. E. Conway and P. L. Bourgault (University of Ottawa) described some studies on the kinetics of self-discharge of nickel - nickel oxide electrodes. The decay of electromotive force and rates of evolution of oxygen had been measured on open circuit over a wide range of concentrations of potassium hydroxide and the kinetics interpreted in terms of a scheme of consecutive reactions for rate- 
determining oxygen evolution at anodic sites on the oxide.

The final session of the meeting, with Dr. S. Schuldiner in the chair, was concerned with the doublelayer and adsorption at electrodes. The correlation between double-layer capacity and kinetics of electrode processes was examined in a paper by Drs. M. Breiter and P. Delahay (Louisiana State University), and Drs. R. S. Hansen and D. A. Hickson (Iowa State College) presented some interesting results on the apparent dependence on frequency of the capacity of the double-layer; relaxation times for water in the double-layer as high as $10^{-2}$ sec. were deduced. This occasioned some discussion, since it was pointed out that even in the ice lattice, where the water is strongly bound, the relaxation time is much smaller (about $10^{-6}$ sec.). Dr. R. Parsons (University of Bristol) read the paper by Prof. A. Frumkin (Academy of Sciences, Moscow) on the influence of surface-active anions on the electro-reduction of persulphate anions at negative potentials ; the acceleration of the reduction of $\mathrm{S}_{2} \mathrm{O}_{8}{ }^{2}$ - which was observed in the presence of surface-active anions was explained in terms of their effect on the potential $\left(\psi_{1}\right)$ at the outer Helmholtz plane in the double-layer. Specific effects of cations on the kinetics required that a local fluctuating $\psi_{1}$-potential due to interaction of the adsorbed anions with cations in the double-layer be considered. A general thermodynamic analysis for the determination of heats of adsorption in ionic systems by electrocapillary studies was given in a paper by Dr. R. Parsons and results obtained for the isotensile heats of adsorption of potassium iodide at mercury were discussed. The meeting concluded with two papers describing the adsorption of hydrochloric acid and aromatic aminium salts at mercury by the electrocapillary method (Drs. E. Blomgren and J. O'M. Bockris, University of Pennsylvania) and the adsorption of methylene blue at mercury by collecting a large number of mercury drops which had fallen through the solution and analysing for the dye carried down in the double-layers of the drops (Drs. J. M. Los and C. K. Tompkins, University of New Brunswick). Some results from studies on the direct determination of adsorption of organic ions at solid metals were presented by Dr. B. E. Conway and Mr. R. G. Barradas in discussion.

Most of the papers presented at the meeting will be published early in 1959 in the Canadian Journal of Chemistry.
B. E. Conway

\section{EAST MALLING RESEARCH STATION}

\section{ANNUAL REPORT}

$\mathrm{T}$ HE annual report of East Malling Research Station for $1957 *$ contains some important research findings. A new semi-dwarfing apple rootstock, $M 26$, is described by W. S. Rogers; it is intermediate in vigour between $M \mathrm{IX}$ and $M$ VII, and so fills a unique place. The elimination of virus from strawberry clones by heat therapy increased the fruit yield of several varieties, though the crop ripened later, and was more prone to Botrytis rot than untreated plants. In Early Cambridge and Rearguard, however, there was excessive vigour and a decrease in yield (W. S. Rogers and Muriel G. Fromow). Rooting and growth of root cuttings from the apple rootstock Crab $C$ declined with increasing age of establishment of the parent plant, according to results obtained by $R$. J. Garner and E. S. J. Hatcher. Raspberry breeding work, by R. L. Knight and Elizabeth Keep, is now mainly concerned with the introduction of resistance to the virus vector $A m p h o r o p h o r a r u b i$ and to cane spot and Botrytis, while interspecific hybrids are being sought between black-currant and gooseberry. The apple breeding work of H. M. Tydeman shows progress towards a late-flowering variety which will be resistant to scab and mildew.

Two papers in the physiological section show that, in the British climate, temperature is perhaps the most important factor in fruit growth. C. R. Hancock and H. W. B. Barlow show that growth-rate of Crab $C$ shoots was related to temperature and day-length, though the final internode length was less dependent on temperature and had little relation with the daily period of light. The same authors found that the

* Kent Incorporated Society for Promoting Experiments in Horticulture. Annual Report of East Malling Research Station, 1st October 1956, to 30th September, 1957. (Forty-flfth year.) Pp. Xxv +173 . 178. $6 d . ; 2.50$ dollars. effects on leaf growth of a summer gale in 1956 were mainly due to the fall in temperature. D. H. Maggs has compared growth of the rootstocks $M$ II and $M$ XVI with differences in time of leaf-break eliminated; the former produced more stem and the latter more root for plants of the same weight. $M$ II had a smaller increase in weight produced per gram of leaf than $M$ XVI.

Symptoms of magnesium deficiency in apple rootstocks can best be eliminated by foliar spraying with Epsom salts. Elsie M. Ford shows that this method is better than soil application and that it is not enough merely to remove the symptoms, for three sprays are necessary to bring increased vigour.

The virus disease known as little cherry causes serious damage in North America, and now A. F. Posnette and R. Cropley have reported it in Great Britain. G. W. F. Sewell and J. F. Wilson report another new trouble in that some common hop garden weeds have been found susceptible to the 'progressive' strain of the hop wilt fungus Verticillium albo-atrum. There were earlier indications that the hop virus 'nettlehead' was in some way linked with nickel content of the plant. J. T. Legg and P. J. Ormerod find that the symptoms of nickel toxicity and of nettlehead are distinct, though presence of the virus is associated with higher contents of some heavy metals than are found in healthy plants. R. S. Pitcher shows that the life cycle of the currant leaf midge Dasyneura tetensi varies considerably from year to year. This brings difficulties of timing control measures and demonstrates the necessity for more persistent toxicants. A study of Blepharidopterus angulatus by R. C. Muir is mainly an evaluation of the capture-recapture method of estimating orchard insect populations. Phytotoxicity studies by A. H. M. Kirby and Margery Bennett show that a number of 